\title{
Analysis of Space Distribution of Scattered Light by Monte Carlo Method in Consideration of Atmospheric Particles
}

\author{
Yoshiro AOKI, Takashi IRIKURA, Tetsuo TANIGUCHI \\ Traffic Safety and Nuisance Research Institute \\ The Ministry of Transport \\ 6-38-1 Sinkawa, Mitaka-shi, Tokyo 181, Japan
}

Paper originally published in Japanese in J. EIEJ, Vol 77 - No.2, 1993

\begin{abstract}
Study on the brightness of airport light systems, especially on how much light is scattered by the atmospheric particles, is important under low visibilities. In this paper, a simulation was programmed to analyze space distribution of scattered light by Monte Carlo method, based on scattering by a single particle calculated through Mie Theory. There is no limitation to the position of particles. Effects of visibility, of particle size distribution, and of light wavelength can be taken into consideration. With this program, we studied the variation of luminance distribution with the change in visibility, position of a pilot looking at the airport and the surroundings when approaching, and so forth. The result shows that the scattering of the airport light may add some influence on the brightness of the airport light in the twilight and at night. The simulation had a slight deviation from the calculation using Koschmieder formula for additional luminance with scattered daylight. Particle size distribution greatly affected airport light scattering, while it had little effect on daylight scattering.
\end{abstract}

\section{Introduction}

Analysis of light scattering in the air is useful to estimate how clearly the lamplight is seen. For example, brightness of airport lights, seen from a pilot approaching a runway, varies with the background luminance, which consists of light reflecting on the runway and directly arriving at the observer (hereinafter called "runway reflection light"), and an additional luminance with lamplight and daylight scattered by atmospheric particles.

There are a variety of light-scattering particles: cloud, rain, fog, mist, etc., whose properties like particle size and refractive index affect scattering; accordingly, there is no one-to-one relationship between the extinction coefficient, $\sigma$, and the scattered light distribution.

Thus, analysis of additional luminance with scattered light, which varies with conditions of the air and the sky, is important for determination of an appropriate luminous intensity of the lamplights.

Measurement based on various combinations of conditions, followed by a detailed and exact analysis, however, is extremely difficult, since it requires exact and durable measurements on luminance distribution in the sky and runway reflection characteristics as well as concentration and size distribution of the scattering particles. This leads to a sufficient consideration of apparent extinction in luminous intensity, but to an insufficient consideration of the effect of scattered lamplight, in determination of runway visual range and the used luminous intensity of the airport lights. Further, Koschmieder's theoretical equation, on the assumption of a uniform background luminance and a minute visual angle of the recognized object, is generally applied to calculation of additional luminance by scattered daylight. ${ }^{1)}$ In this study, we produced a simulation program to analyze the space distribution of scattered light using the Monte Carlo Method on the basis of scattering characteristics obtained through Mie's equation for scattering. It revealed how the additional luminance with scattered airport lamplight and scattered daylight depends on the characteristics of scattering particles, of lamplight, and of daylight, as well as the observing position, when a pilot looks at the runway and the surroundings while approaching. The results are presented below. 


\section{Analytical Method by Simulation}

\subsection{Mie Equation for Scattering}

Mie and Debye derived a theory to obtain the intensity of scattering from Maxwell equation for electromagnetic waves. According to the Mie theory, where a plain wave of a unit illuminance is projected on a spherical particle, scattering intensity $\mathrm{I}(\alpha, \theta)$ and scattering efficiency $\mathrm{K}(\alpha)$ are the functions of scattering angle $\theta$ (the relative angle between projection and scattering), refractive index of the particle $\mathrm{m}$, and size parameter $\alpha$ which is equal to $2 \pi \% / \lambda$ ( $r$ : particle radius $\lambda$ : light wavelength).

$$
\begin{aligned}
& \mathrm{I}(\alpha, \theta)=\lambda^{2}\left\{\mathrm{i}_{1}+\mathrm{i}_{2}\right\} / 8 \pi^{2} \\
& \mathrm{~K}(\alpha)=\left(2 / \alpha^{2}\right) \sum_{\mathrm{v}=1}^{\infty}(2 \mathrm{v}+1)\left(\left|\mathrm{a}_{\mathrm{v}}\right|^{2}+\left|\mathrm{b}_{\mathrm{v}}\right|^{2}\right)
\end{aligned}
$$

where, $i_{1}$ and $i_{2}$ are as follows:

$$
\begin{aligned}
& i_{1}=\left|\sum_{v=1}^{\infty} \frac{2 \mathrm{v}+1}{\mathrm{v}(\mathrm{v}+1)}\left\{\mathrm{a}_{\mathrm{v}} \frac{\mathrm{P}_{\mathrm{v}}^{\mathrm{v}}(\cos \theta)}{\sin \theta}+\mathrm{b}_{\mathrm{v}} \frac{\mathrm{dP}_{\mathrm{v}}^{\mathrm{l}}(\cos \theta)}{\mathrm{d} \theta}\right\}\right|^{2} \\
& \mathrm{i}_{2}=\left|\sum_{\mathrm{v}=1}^{\infty} \frac{2 \mathrm{v}+1}{\mathrm{v}(\mathrm{v}+1)}\left\{\mathrm{b}_{\mathrm{v}} \frac{\mathrm{P}_{\mathrm{v}}^{1}(\cos \theta)}{\sin \theta}+\mathrm{a}_{\mathrm{v}} \frac{\mathrm{dP}_{\mathrm{v}}(\cos \theta)}{\mathrm{d} \theta}\right\}\right|^{2}
\end{aligned}
$$

$\mathrm{P}_{\mathrm{v}}{ }_{\mathrm{v}}(\cos \theta)$ is Legendre's multinomial. $\mathrm{a}_{\mathrm{v}}$ and $\mathrm{b}_{\mathrm{v}}$ consist of the primary and secondary Ricatti-Bessel Functions, $\psi_{v}$ and $\zeta_{\mathrm{v}}$, and their derivatives.

$$
\begin{aligned}
& a_{v}=\frac{\psi_{v}^{\prime}(m \alpha) \psi_{v}(\alpha)-m \psi_{v}(m \alpha) \psi_{v}^{\prime}(\alpha)}{\psi_{v}^{\prime}(m \alpha) \zeta_{v}(\alpha)-m \psi_{v}(m \alpha) \zeta_{v}^{\prime}(\alpha)} \\
& b_{v}=\frac{m \psi_{v}^{\prime}(m \alpha) \psi_{v}(\alpha)-\psi_{v}(m \alpha) \psi_{v}^{\prime}(\alpha)}{m \psi_{v}^{\prime}(m \alpha) \zeta_{v}(\alpha)-\psi_{v}(m \alpha) \zeta_{v}^{\prime}(v)}
\end{aligned}
$$

When the refractive index is a complex number $m=n+$ $\mathrm{kj}$ ( $\mathrm{k}$ is an absorption -coefficient), a beam of light is extinguished with scattering and absorption, where the extinction efficiency $\operatorname{Ke}(\alpha)$ is as follows:

$$
\operatorname{Ke}(\alpha)=\left(2 / \alpha^{2}\right) \sum_{\mathrm{v}=1}^{\infty}(2 \mathrm{v}+1) \operatorname{Re}\left(\mathrm{a}_{\mathrm{v}}+\mathrm{b}_{\mathrm{v}}\right)
$$

When the absorption coefficient $\mathrm{k}=0, \mathrm{~K}(\alpha)$ becomes equal to $\mathrm{Ke}(\alpha)$. Equations (1) - (7) are called Mie equations for scattering.

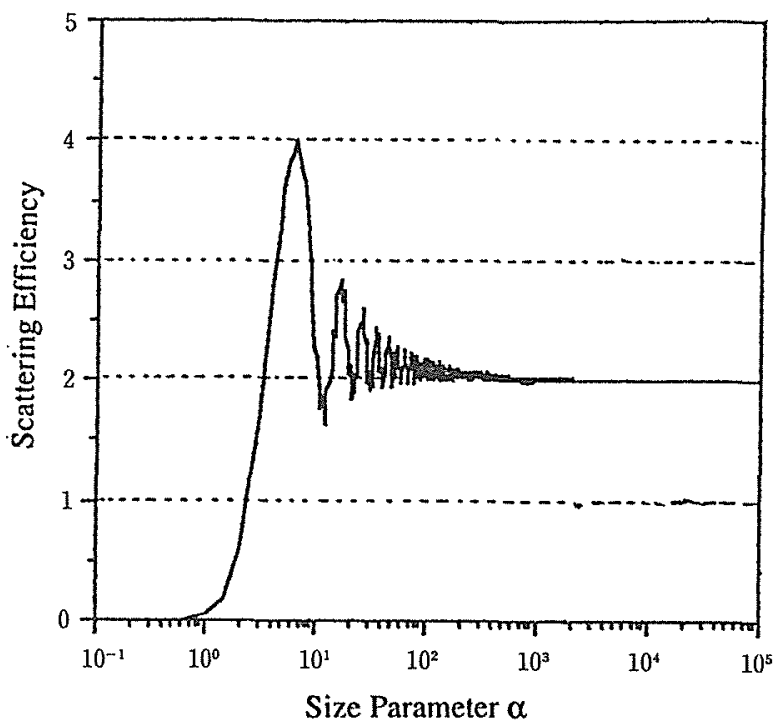

Fig. 1 Scattering Efficiency K $(\alpha)$ vs Size Parameter $\alpha$

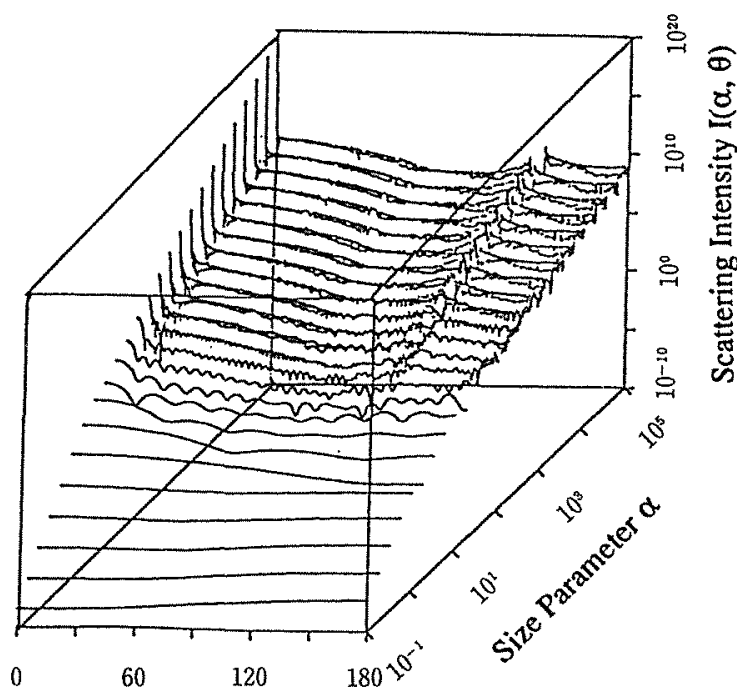

Scattering Angle $\theta$ (degree)

Fig. 2 Scattering Intensity vs Size Parameter $\alpha$ and Scattering Angle $\theta$

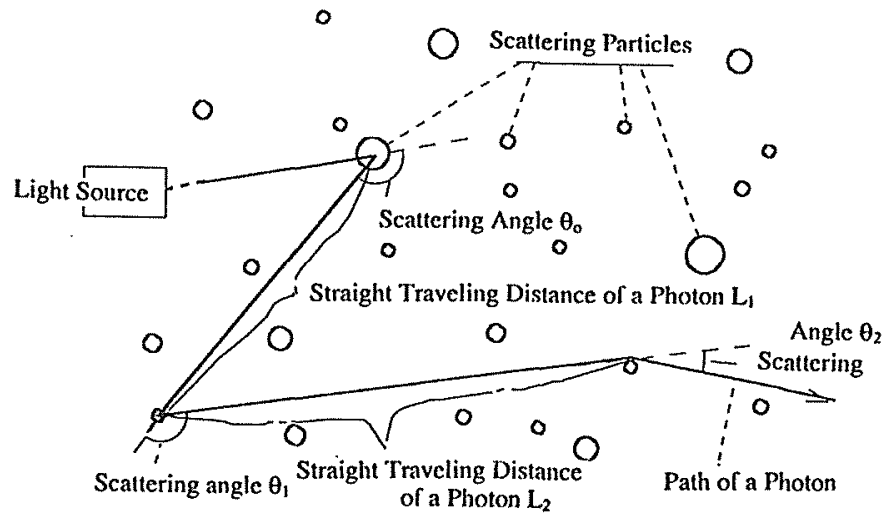

Fig. 3 Photon traveling through the Air Containing Scattering Particles 


\subsection{Scattering Characteristics versus Size Parameter $\alpha$}

Scattering efficiency $\mathrm{K}(\alpha)$ and scattering intensity $\mathrm{I}(\alpha, \theta)$ obtained through equations (1) - (6) with a size parameter $\alpha$ are shown in Fig. 1 and 2, where calculations were made with the refractive index assumed as:

$$
\mathrm{m}=1.33+0.00 \mathrm{j}
$$

Scattering efficiency $\mathrm{K}(\alpha)$ increases until $\alpha$ exceeds 5 , and thereafter oscillationally converges to 2 .

In the scattering intensity $\mathrm{I}(\alpha, \theta)$, the ratio of the forward scattering against total scattering increases, as $\alpha$ increases.

\subsection{Analysis of Space Distribution of Scattered Light by Monte Carlo Method}

Extinction coefficient, $\sigma[/ \mathrm{m}]$, of light traveling in the air is obtained from the concentration distribution, $n_{a}(r)\left[/ \mathrm{m}^{3}\right]$, of scattering particles, the distribution of probability density $f(\lambda)$, for light wavelength, and scattering efficiency, $K(\alpha)$, which is shown in Fig. 1.

$$
\sigma=\pi \int_{0}^{\infty} \int_{0}^{\infty} \mathrm{r}^{2} \mathrm{n}_{\mathrm{a}}(\mathrm{r}) \mathrm{f}(\lambda) \mathrm{K}(\alpha) \mathrm{drd} \lambda
$$

It can be predicted probability-wise, using $\sigma$, how much distance a photon travels straight or it never scatters any more, following a release or the previous scattering. Since the probability for a photon to travel straight the distance $x$ without affected by particles is expressed by exp $(-\sigma x)$, the predicted distance for the next scattering, $\mathrm{L}$, is calculated as follows:

$$
\mathrm{L}=-\ln (\operatorname{ran} 1) / \sigma
$$

where, ranl is a uniform random number between 0 and 1.
Probability density distribution, $\mathrm{F}(\alpha, \theta)$, of a scattering angle is expressed by eq. 10 .

$$
\mathrm{F}(\alpha, \theta)=\mathrm{w}(\theta) \mathrm{I}(\theta) / \int_{0}^{\pi} \mathrm{w}(\theta) \mathrm{I}(\theta) \mathrm{d} \theta
$$

where, $\mathrm{w}(\theta)$ is a solid angle at $\theta$. A scattering angle $\theta$, at each scattering point, can be predicted.

$$
\theta=\mathrm{F}^{-1}(\alpha, \operatorname{ran} 2)
$$

where, ran2 is a uniform random number between 0 and 1.

In this manner, we can predict position and direction of the each scattering consecutively; the basic conception is shown in Fig. 3.

We selected a plural number of photons, and superposed their traveling paths to obtain a statistical distribution; luminance distribution for a luminous element and a reflector, seen through the air containing scattering particles by the observer existing at an arbitrary position and in an arbitrary direction, can be estimated. Based on the scattering characteristics of a single particle obtained through Mie equations, the space distribution of scattered light, in the presence of a plural number of particles, can be simulated by the Monte Carlo Method; the basic flowchart is shown in Fig. 4.

In this method, luminance distributions at all observation points and in all directions can be calculated at a time. An accurate and detailed analysis is possible, because there is no limitation to the position of particles and the particle size distribution and the wavelength of light can be taken into consideration. But the time required for calculation is long. A theoretical luminance distribution is obtained if both the number of mock photons $\mathrm{N}$ and the maximum number of scattering is counted up to infinity, which

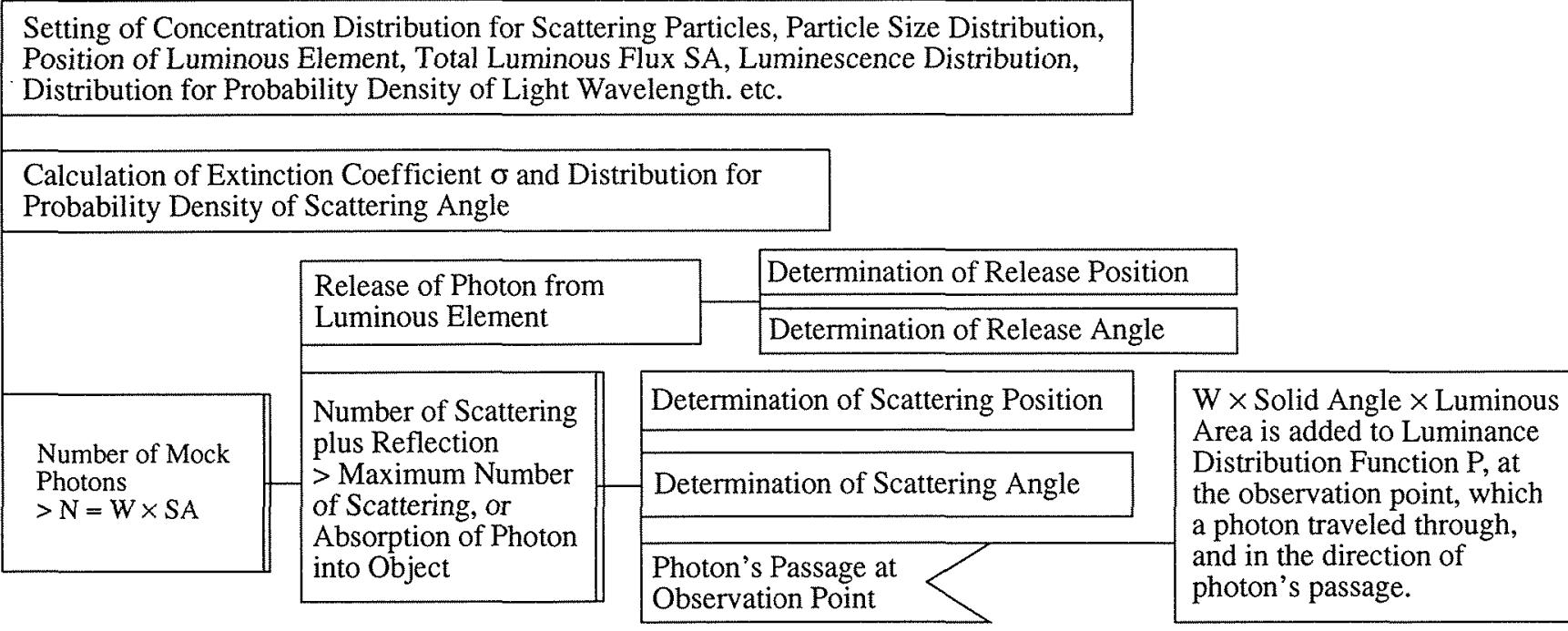

Fig. 4 Basic Flowchart for Simulation of Space Distribution of Scattered Light 
requires an infinite length of time for calculation; Certain limitations should be imposed on these factors. In this study, the total number of mock photons was limited to the range between $10^{6}$ and $10^{7}$. Further, in the case of airport light scattering, the maximum number of scattering was assumed to be 20, whereas in the case of daylight scattering, the number was counted up to infinity. Time required for the simulation of space distribution of scattered light was reduced by previously calculating the scattering efficiency and intensity through Mie equations. The processing speed of the computer was approximately 0.5 MFLOPS (real number with double accuracy) in LINPACK. and the time required for a simulation was approximately $5-20$ hours.

\subsection{Particle Size Distribution and Distribution of Probability Density for Light Wavelength}

The particle size distribution $n_{a}(r)$ and the distribution of probability density for light wavelength $f(\lambda)$, which are required for obtaining the extinction coefficient and the distribution of probability density for scattering angles, were set as follows:

\subsubsection{Particle Size Distribution}

Although the particle size distribution of scattering particles is not necessarily determined on one-on-one basis for the mean particle radius, the function for the distribution at each mean particle radius $\bar{r}$ was assumed, based on the past surveys, ${ }^{2)-5)}$ as follows:

(1) When the mean particle radius is below $1 \mu \mathrm{m}$; Young's distribution function ${ }^{2) 3)}$ (distribution for a continental haze):

$$
\begin{aligned}
& n_{a}(r) \cong r^{-4} \\
& \left(r_{1} \leq r \leq r_{2} \text {, where } r_{1} \text { was assumed to be } r_{2} / 100\right)
\end{aligned}
$$

Then $\overline{\mathrm{r}}=\mathrm{r}_{1} \times 1.5$

(2) When the mean particle radius is $1-100 \mu \mathrm{m}$; Deirmenjian's distribution function ${ }^{2 / 4)}$ (distribution for a cumulus cloud):

$$
\begin{aligned}
& \mathrm{n}_{\mathrm{a}}(\mathrm{r}) \cong\left[(\mathrm{r} / \mathrm{q}) \mathrm{e}^{1-\mathrm{r} / \mathrm{q}}\right]^{\mathrm{b}} \\
& (0 \leq \mathrm{r} \leq \infty, \text { where } \mathrm{b} \text { was assumed to be } 6.0) \\
& \text { Then } \overline{\mathrm{r}}=\mathrm{q} \times 1.167
\end{aligned}
$$

(3) When the mean particle radius is above $100 \mu \mathrm{m}$ : Laws $\&$ Parsons's distribution function ${ }^{4) 5)}$ (distribution for rain):

$$
\begin{aligned}
& \mathrm{n}_{\mathrm{a}}(\mathrm{r}) \cong 10^{-\mathrm{Br}}(0 \leq \mathrm{r} \leq \infty) \\
& \text { Then } \overline{\mathrm{r}}=0.4343 / \mathrm{B}
\end{aligned}
$$

\subsubsection{Distribution of Probability Density for Light Wavelength}

The distribution, $f(\lambda)$, of probability density for light wavelength was obtained on the following assumption:

(a) Spectral distribution of airport light is the CIE standard illuminant $\mathrm{A}(\lambda)$

(b) Spectral distribution of daylight is the CIE standard daylight $\mathrm{D}_{65}(\lambda)$.

(c) Spectral luminance efficiency is the CIE standard spectral luminous efficiency for photopic vision $V(\lambda)$.

$$
\begin{aligned}
& <\text { Lamplight }>\mathrm{f}(\lambda)=\mathrm{V}(\lambda) \mathrm{D}_{65}(\lambda) / \int_{0}^{\infty} \mathrm{V}(\lambda) \mathrm{D}_{65}(\lambda) \mathrm{d} \lambda \\
& <\text { Daylight }>\mathrm{f}(\lambda)=\mathrm{V}(\lambda) \mathrm{A}(\lambda) / \int_{0}^{\infty} \mathrm{V}(\lambda) \mathrm{A}(\lambda) \mathrm{d} \lambda
\end{aligned}
$$

\begin{tabular}{|c|c|c|}
\hline & $\begin{array}{l}\text { Lamplight } \\
\text { Scattering }\end{array}$ & $\begin{array}{l}\text { Daylight } \\
\text { Scattering }\end{array}$ \\
\hline \multirow{2}{*}{$\begin{array}{l}\text { Existing Range of } \\
\text { Scattering }\end{array}$} & $\begin{array}{l}\text { Ground Surface } \\
-\infty\end{array}$ & $\begin{array}{l}\text { Ground Surface - } \\
80 \text { or } 110 \mathrm{~m}\end{array}$ \\
\hline & Particles & stant in this range) \\
\hline $\begin{array}{l}\text { Total Number of } \\
\text { Mock Photons }\end{array}$ & \multicolumn{2}{|c|}{ Approximately $10^{6}-10^{7}$} \\
\hline $\begin{array}{l}\text { Max. Number of } \\
\text { Scattering }\end{array}$ & 20 & $\infty$ \\
\hline Refractive Index m & \multicolumn{2}{|c|}{1.33 (Refractive Index of water) } \\
\hline Visibility $V_{5}$ & $400-15000 \mathrm{~m}$ & $400-5000 \mathrm{~m}$ \\
\hline Observation Point & \multicolumn{2}{|c|}{$\begin{array}{l}\text { Horizontal Distance from Runway } \\
\text { Threshold: } 0-1.6 \mathrm{~km}\end{array}$} \\
\hline $\begin{array}{l}\text { Mean Particle } \\
\text { Radius } \bar{r}\end{array}$ & \multicolumn{2}{|c|}{$0.3-300 \mu \mathrm{m}$} \\
\hline $\begin{array}{c}\text { Interval of } r \text {, at } \\
\text { Particle Size } \\
\text { Distribution } n_{a}(r)\end{array}$ & \multicolumn{2}{|c|}{$\begin{array}{c}\text { Radius } 0.038 \times \mathrm{r} \text { for equation }(12) \\
0.222 \mu \mathrm{m} \text { for equation }(13) \\
0.00389 \times \mathrm{r} \text { for equation }(14)\end{array}$} \\
\hline $\begin{array}{l}\text { Interval of Wave- } \\
\text { length } \lambda \text { at } f(\lambda)\end{array}$ & \multicolumn{2}{|c|}{$1 \mathrm{~nm}$} \\
\hline $\begin{array}{l}\text { Interval of } \theta \text { at } \\
\mathrm{F}(\alpha, \theta)\end{array}$ & \multicolumn{2}{|c|}{0.1 degree } \\
\hline $\begin{array}{c}\text { Interval of } \log \alpha \\
\text { at } F(\alpha, \theta)\end{array}$ & \multicolumn{2}{|c|}{0.0625} \\
\hline
\end{tabular}

\subsection{Parameters for Calculation}

Parameters used for calculation in this study are shown in Table 1. Since the important weather condition for this

Table 1 Parameters for Calculation 
study is in a low visibility condition with a humidity close to $100 \%$, the following equation may apply for all the range from haze to rain for calculation of scattering characteristics:

$$
\text { Refractive index } \mathrm{m}=1.33+0.00 \mathrm{j}
$$

although the refractive index of haze particles at a low relative humidity generally differs from that of water.

\section{Results of Analysis and Discussions}

The background luminance for a pilot approaching the runway is, as shown in Fig. 5, the sum of runway reflection light, scattered daylight, and scattered lamplight.

The additional luminance caused by these scattered lamplight and daylight, which affects the brightness for a pilot looking at the airport light, will be consecutively obtained below.



Fig. 5 Apparent Background Luminance Recognized by Approaching Pilot

\subsection{Scattering of Airport Light}

Following the basic flowchart shown in Fig. 4, we calculated the luminance distribution for a halo at each airport light, and then superposed them; thus, the total quantity of scattered lamplight for a complex light system like airport lights has become obtainable.

Selecting the lamplights (with 845 lights) on Approach Runway R16 at Narita Airport as a model, we are going to clarify how the additional luminance at points A, B and C, which are in the vicinity of the aiming point, are affected by the following factors: visibility $\mathrm{V}_{5}$ obtained for the visual contrast threshold 0.05 , which is calculated as $\mathrm{V}_{5}=$ $2.996 / \sigma$; and position of the pilot, expressed by the horizontal distance from a runway threshold at the approach slope of 3 degrees. The intersection of the pilot's approach path with the runway surface was assumed to be $500 \mathrm{~m}$ from a runway threshold at the runway centerline.

Visibilities $V_{5}$, shown in Fig. 9 - Fig. 11, were calculated through eq. (17). Transmittance $T$ (i.e., the ratio of light, compared with the good visibility, reaching the receptor from the luminous element), used in eq. (17), was simulated by Monte Carlo Method shown in Fig. 4, and the specification of the transmissometer, used for the simulations, were those of the Narita Airport RVR (Runway Visual Range) observation apparatus (see Table 2).

$$
\begin{aligned}
\mathrm{V}_{5} & =2.996 / \sigma=-2.996 \times \mathrm{D}_{\mathrm{r}} / \log \mathrm{T} \\
& =-2.996 \times \mathrm{D}_{\mathrm{r}} / \log \left(\mathrm{T}_{1}+\mathrm{T}_{2}\right)
\end{aligned}
$$

where, $D_{\mathrm{r}}$ : Distance between Projector and Receptor

$\mathrm{T}_{1}$ : Components of Direct Light

$\mathrm{T}_{2}$ : Components of Scattered Light

Table 2. Specification for Transmissometer Used for RVR Observation Apparatus at Narita Airport

\begin{tabular}{|l|l|}
\hline $\begin{array}{l}\text { Distance between Projector } \\
\text { and Receptor }\end{array}$ & $150 \mathrm{~m}$ \\
\hline $\begin{array}{l}\text { View (Beam) Angle for } \\
\text { Projector and Receptor }\end{array}$ & 3 degrees \\
\hline $\begin{array}{l}\text { Light Wavelength of Light } \\
\text { Source }\end{array}$ & $0.9 \mathrm{~mm}$ (Near Infrared) \\
\hline
\end{tabular}

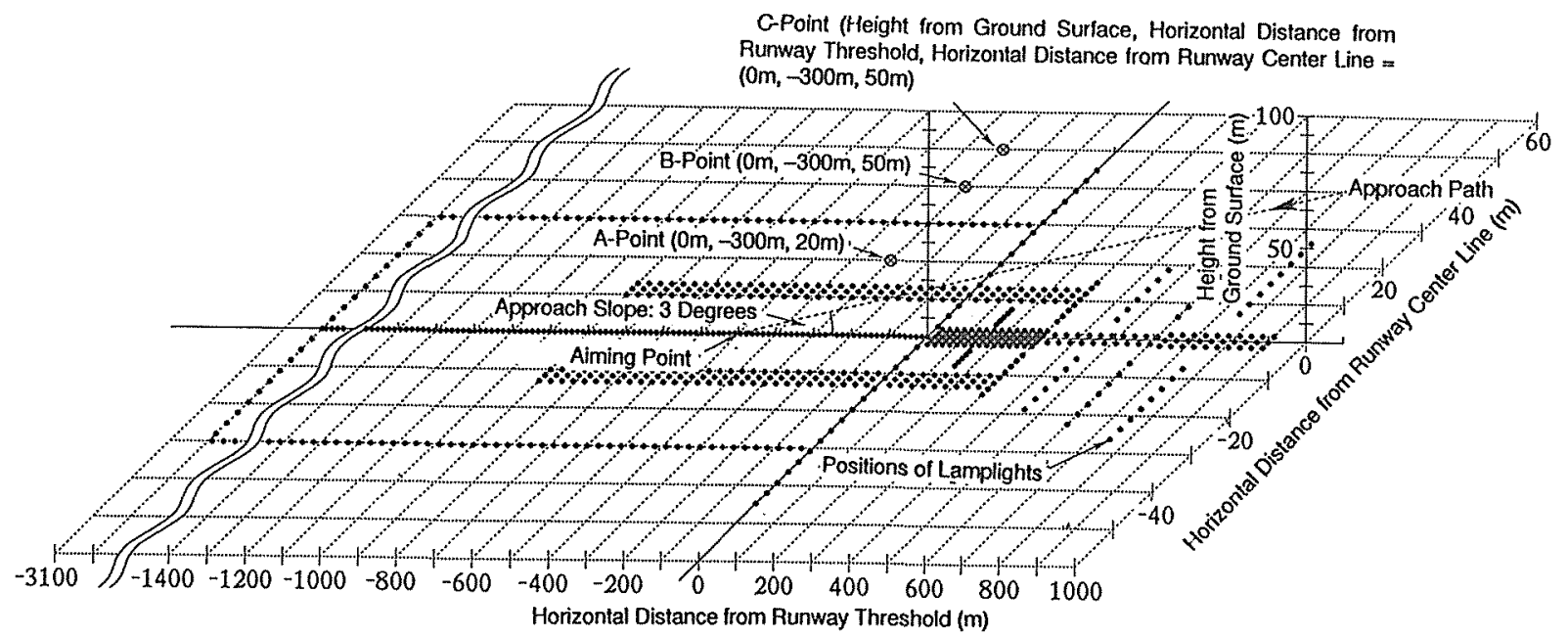

Fig. 6 Model of Airport Lights 
This simulated visibility $V_{5}$ does not coincide with the theoretical value obtained from equation (18) using with the same particle size distribution $\mathrm{n}_{\mathrm{a}}(\mathrm{r})$ for lamp- and daylights; the theoretical values were calculated from scattering efficiency $K(\alpha)$, based on Mie theory (see Fig. 7).

$$
\begin{aligned}
\mathrm{V}_{5} & =2.996 / \sigma \\
& =2.996 /\left(\pi \int_{0}^{\infty} \int_{0}^{\infty} \mathrm{r}^{2} \mathrm{n}_{\mathrm{a}}(\mathrm{r}) \mathrm{f}(\lambda) \mathrm{K}(\alpha) \mathrm{drd} \lambda\right)
\end{aligned}
$$

Reasons for the difference may be as follows:

a) The wavelengths of light, used for the transmissometer in the RVR observation apparatus, differs from those of lamp- and daylights.

b) Because the projector and the receptor for the transmissometer have a range of 3 degrees of the view (beam) angle, the receptor receives not only the unscattered direct light but also the scattered light around the luminous source $\left(T=T_{1}+T_{2}\right)$.

The difference in visibility for wavelength, a), which is the difference of theoretical visibility $V_{5}$ for $0.9 \mu \mathrm{m}$, the near infrared ray, from theoretical visibility $V_{5}$ for day- and lamplights, occurs below the mean particle radius of 0.7 $\mu \mathrm{m}$. And then near infrared ray has a higher transmittance and a higher theoretical visibility $\mathrm{V}_{5}$ (see Fig. 7).

Effect of receiving scattered light, b), increases with the increase in mean particle radius, which causes increase in the ratio forward scattering (see Fig. 2), leading to a decrease in the ratio of theoretical visibility $V_{5}$ for the near infrared ray against the simulated visibility. This ratio converges to 0.5 as shown in Fig. 7 ; back calculation of scattering efficiency, with simulated $V_{5}$ put into eq. (18), leads to convergence to 1 , instead of 2 .

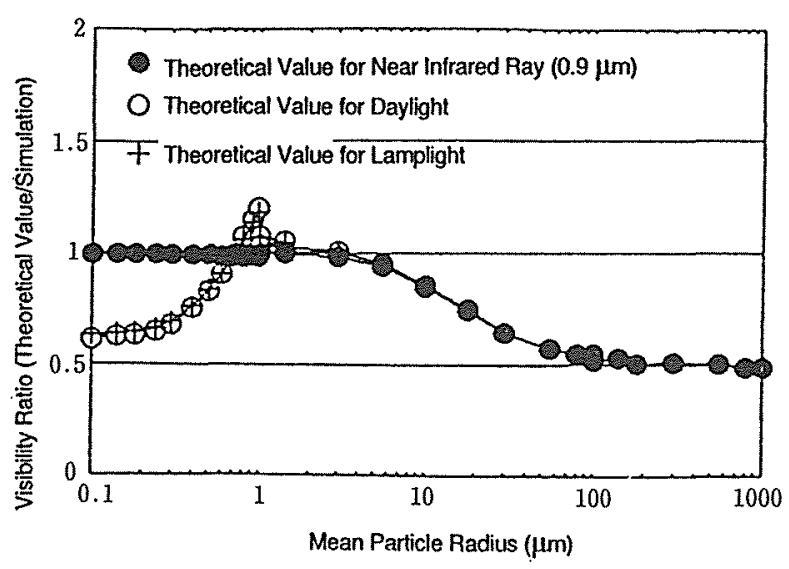

Fig. 7 Difference in Visibility vs Difference Light Souce

The extinction efficiency (i.e. scattering efficiency for transparent object) for a large object becomes 2 according to Mie's theory as shown in Fig. 1, whereas the apparent extinction efficiency becomes 1 , which means that the apparent extinction section is equal to the geometrical section; this contradiction was indicated by H.S.W. Massery et al. ${ }^{6}$, with which our result coincides well.

Corrected scattering efficiency $\mathrm{K}^{\prime}(\alpha)$ is shown in Fig. 8 , where scattered light at the scattering angles between 0 and 0.2 minute, which is half the maximum visual angle that causes the light source to be seen as point source in a photopic vision, were eliminated. The corrected scattering efficiency $\mathrm{K}^{\prime}(\alpha)$ also converged to 1 , which was confirmed up to $\alpha=10^{5}$ : the correction with visuo-psychological elements was shown to cause a geometrical convergence of the scattering efficiency.

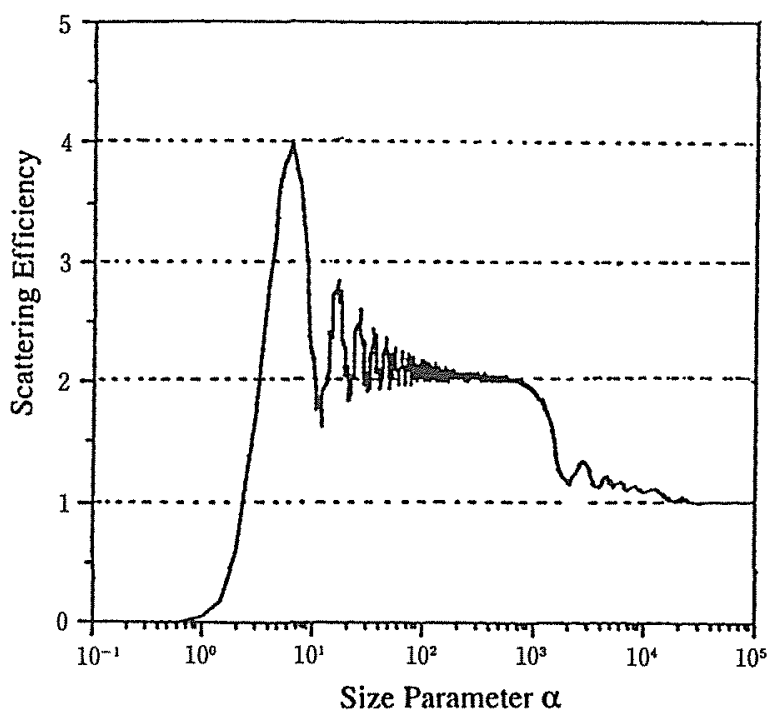

Fig. 8 Corrected Scattering Efficiency $\mathrm{K}^{\prime}(\alpha)$ vs Size Parameter $\alpha$

$K(\alpha)$, uncorrected, was used for Monte Carlo simulation of scattered airport light and scattered daylight.

Difference in visibility $\mathrm{V}_{5}$ in daylight and lamplight was not apparent, due to little difference in the mean wavelengths, $0.58 \mu \mathrm{m}$ and $0.56 \mu \mathrm{m}$, respectively.

Luminous intensity distribution was set in accordance with ICAO Standard as shown in Table 3. Luminous intensity set on the highest tap. The particle concentration assumed to be uniform in the space.

Additional luminance with scattered lamplights of approach runway, obtained under these conditions, are shown in Fig. 9.

From the results with the visibilities $V_{5}$ of $400 \mathrm{~m}$ and $1500 \mathrm{~m}$, when the observation distance (horizontal distance from the runway threshold plus $500 \mathrm{~m}$ ) is close to visibility $\mathrm{V}_{5}$, the additional luminance mostly reaches its maximum with any particle distributions and at any observation point (A, B or C). Visual range for each lamplight does not completely coincide with visibility $\mathrm{V}_{5}$, changing with the luminous intensity used, but they normally are close. The maximum value of the additional luminance differs with 
different particle size distribution and visibility $V_{5}$, but at point $A$, it was $6 \mathrm{~cd} / \mathrm{m}^{2}$ at the lowest, which is equal to the value with visibility $V_{5}$ of $400 \mathrm{~m}$. The visual distance each lamplight does not increase to a large extent even though the luminous intensity is increased in low visibility, in the twilight and at night, since it also increases the background luminance, which is considered to be interfering with the increase in the visual distance. As the pilots come closer to the runway, the background luminance steeply decreases and the apparent luminous intensity of lamplight increases. Therefore then the pilots might cause glare if the controllers increase the lamp current too much; in the twilight and at night, the scattered lamplight might affect the brightness of lamplight, which should be taken into consideration. Particle size distribution has also been shown to greatly affect additional luminance, which reached the maximum at the mean particle radius of 3.0 $\mu \mathrm{m}$, decreasing toward both direction, larger and smaller sides of the distribution. This is because of the increased ratio of the light scattered at angles of 1 minute -6 degrees, at the mean particle radius of $3.0 \mu \mathrm{m}$; scattered light diffuses at $0.3 \mu \mathrm{m}$, the smaller side, and it concentrates on the vicinity of each lamp at $30 \mu \mathrm{m}$ and $300 \mu \mathrm{m}$, the larger side.
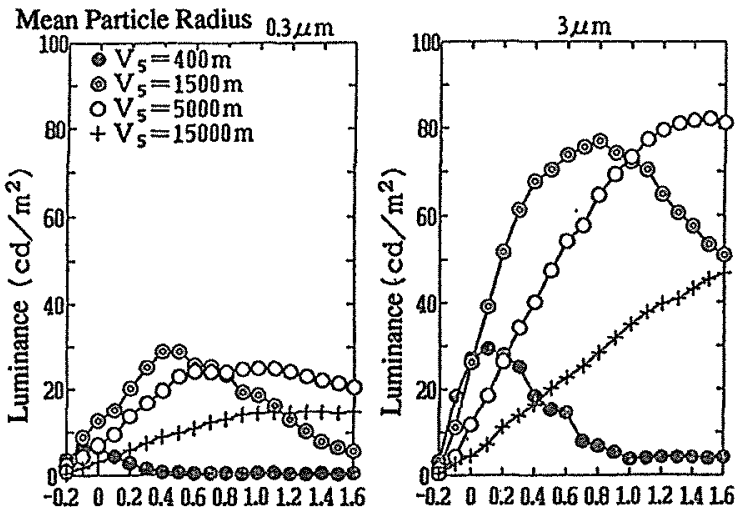

Horizontal Distance from Runway Threshold $(\mathrm{km})$
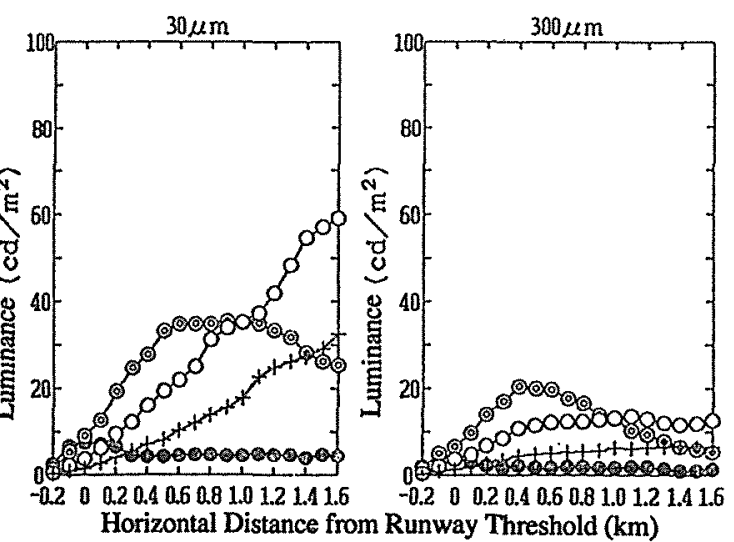

(a) Point A
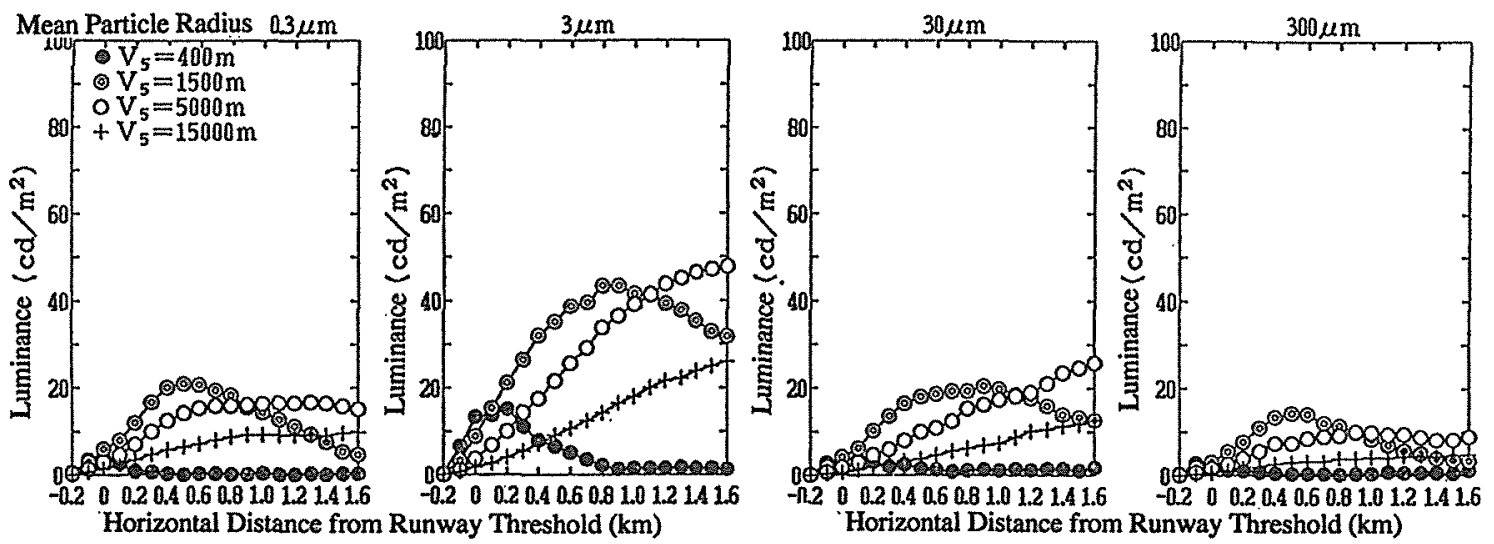

(b) Point B
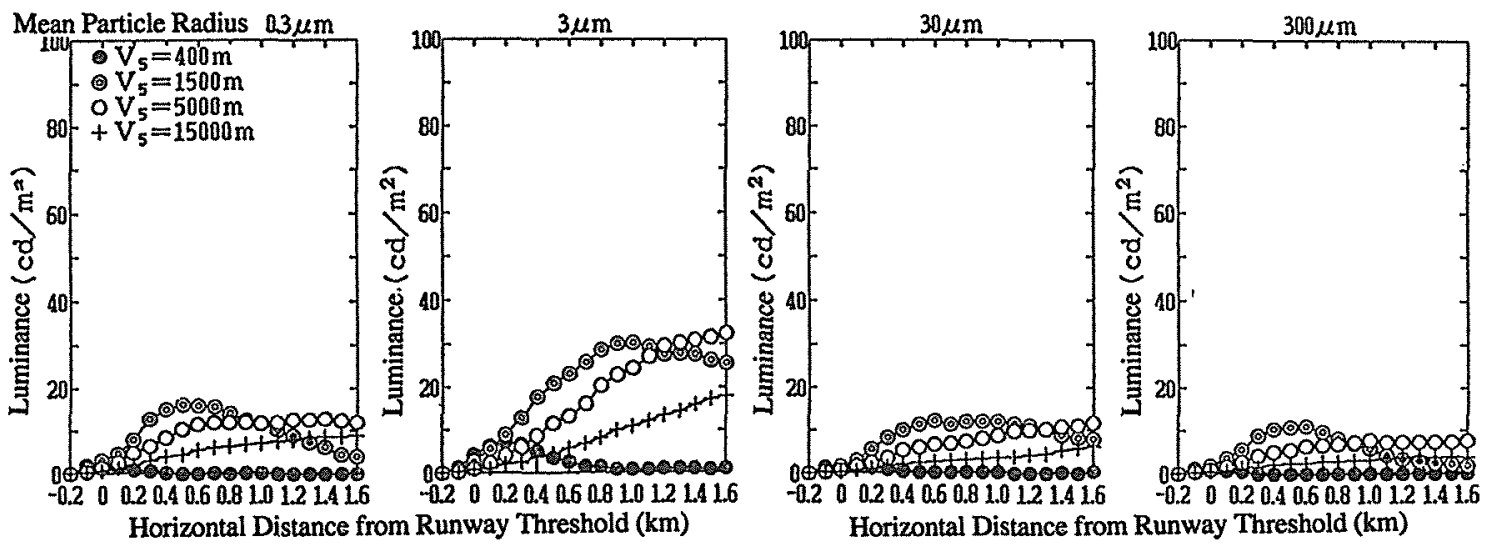

(c) Point C

Fig. 9 Additional Luminance with Scattered Lamplights of Airport Runway 
Table 3. Luminous Intensity Distribution Used for Calculation

\begin{tabular}{|l|c|l|}
\hline & $\begin{array}{l}\text { Center } \\
\text { Luminous } \\
\text { Intensity }\end{array}$ & $\begin{array}{l}50,10,5,1 \% \\
\text { Points from CLI }\end{array}$ \\
\hline $\begin{array}{l}\text { Approach Centerline - } \\
\text { and Crossbar Lights }\end{array}$ & $24,000 \mathrm{~cd}$ & $\begin{array}{l}10,14,17,30 \\
\text { degrees from } \\
\text { center }\end{array}$ \\
\hline $\begin{array}{l}\text { Approach Side Row } \\
\text { Lights }\end{array}$ & $6,000 \mathrm{~cd}$ & $\begin{array}{l}10,14,17,30 \\
\text { deg. from center }\end{array}$ \\
\hline $\begin{array}{l}\text { Runway Threshold } \\
\text { Lights }\end{array}$ & $12,000 \mathrm{~cd}$ & $\begin{array}{l}6,8,10,18 \mathrm{deg} . \\
\text { from center }\end{array}$ \\
\hline $\begin{array}{l}\text { Threshold Wing Bar } \\
\text { Lights }\end{array}$ & $12,000 \mathrm{~cd}$ & $\begin{array}{l}1014,17,30 \\
\text { deg. from center }\end{array}$ \\
\hline $\begin{array}{l}\text { Touchdown Zone } \\
\text { Lights }\end{array}$ & $6,000 \mathrm{~cd}$ & $\begin{array}{l}6,8,10,18 \mathrm{deg} . \\
\text { from center }\end{array}$ \\
\hline $\begin{array}{l}\text { Runway Center Line } \\
\text { Lights }\end{array}$ & $6,000 \mathrm{~cd}$ & $\begin{array}{l}6,8,10,18 \mathrm{deg} . \\
\text { from center }\end{array}$ \\
\hline Runway Lights & $12,000 \mathrm{~cd}$ & $\begin{array}{l}10,14,17,30 \\
\text { deg. from center }\end{array}$ \\
\hline Runway End Lights & $3,000 \mathrm{~cd}$ & $\begin{array}{l}6,8,10,18 \text { deg. } \\
\text { from center }\end{array}$ \\
\hline Runway End Lights & $3,000 \mathrm{~cd}$ & $\begin{array}{l}6,8,10,18 \text { deg. } \\
\text { from center }\end{array}$ \\
\hline
\end{tabular}

Note: Luminous intensity distribution was assumed to have a distribution like concentric circles with a maximum at the center.

\subsection{Scattering of Daylight}

Simulation was made on the effect of daylight, shining on and scattered by particles, on additional luminance at the aiming point during approach, when the particles exist in a layer between $0-110 \mathrm{~m}$ or $0-80 \mathrm{~m}$ above ground only with a clear atmosphere thereabove. The sky condition seen from above the particles layer, which is the same as that of the sky seen from ground when the atmosphere is clear, was assumed to be either the CIE standard overcast sky or the CIE standard clear sky.

\subsubsection{In CIE Standard Overcast Sky}

Additional luminances with scattered daylight and with runway reflection light, simulated by Monte Carlo Method in CIE standard overcast sky, are shown in Fig. 10. The particles layer was assumed to exist between $0-110 \mathrm{~m}$ above ground, and the illuminance from unobstructed sky above the layer was assumed to be $25,000 \mathrm{~lx}$. Additional luminance with scattered daylight plus runway reflection light was shown to reach possibly more than 3 times the road surface luminance of approximately $1,100 \mathrm{~cd} / \mathrm{m}^{2}$ in good visibility, where the road surface is assumed to have reflection characteristics of $15 \%$ reflectance and perfect diffusion. Additional luminance continuously increased even beyond visibility $\mathrm{V}_{5}$.

$$
\mathrm{L}_{\mathrm{r}}=\mathrm{L}_{0} \exp (-\sigma \mathrm{R})+\mathrm{L}_{\mathrm{h}}(1-\exp (-\sigma \mathrm{R}))
$$

where, R: Observation distance

$\mathrm{L}_{0}$ : Road surface luminance in good visibility

$\mathrm{L}_{\mathrm{h}}$ : Sky luminance on horizon in direction of observation

Comparison of this simulated result with road surface luminance $L_{r}$, which was calculated through Koschmieder equation (eq. 19) ${ }^{7)}$ for horizontal vision using the simulated $\mathrm{L}_{0}$ and $\mathrm{L}_{\mathrm{h}}$, showed: the simulated luminance was generally lower at the observation distance (horizontal distance from the runway end plus $500 \mathrm{~m}$ ) equal to visibility $V_{5}$ or lower, then became equal at slightly longer distance, and finally, the simulated luminance tended to be higher beyond that range. This is because of the approximation in the Koschmieder equation that the background luminance is uniform and the visual angle of the recognized object is minute, $0.1-1$ degree. Actually, the visual angle for the runway is not minute; accordingly, the simulated luminance increases slower than the luminance calculated Koschmieder equation when the distance from runway increases. Also, with the increase in the distance from the runway and the height of the airplane, the apparent luminance in the sky increases; accordingly, the increase in additional luminance continues beyond visibility $V_{5}$. These reasons lead to the difference between the simulated
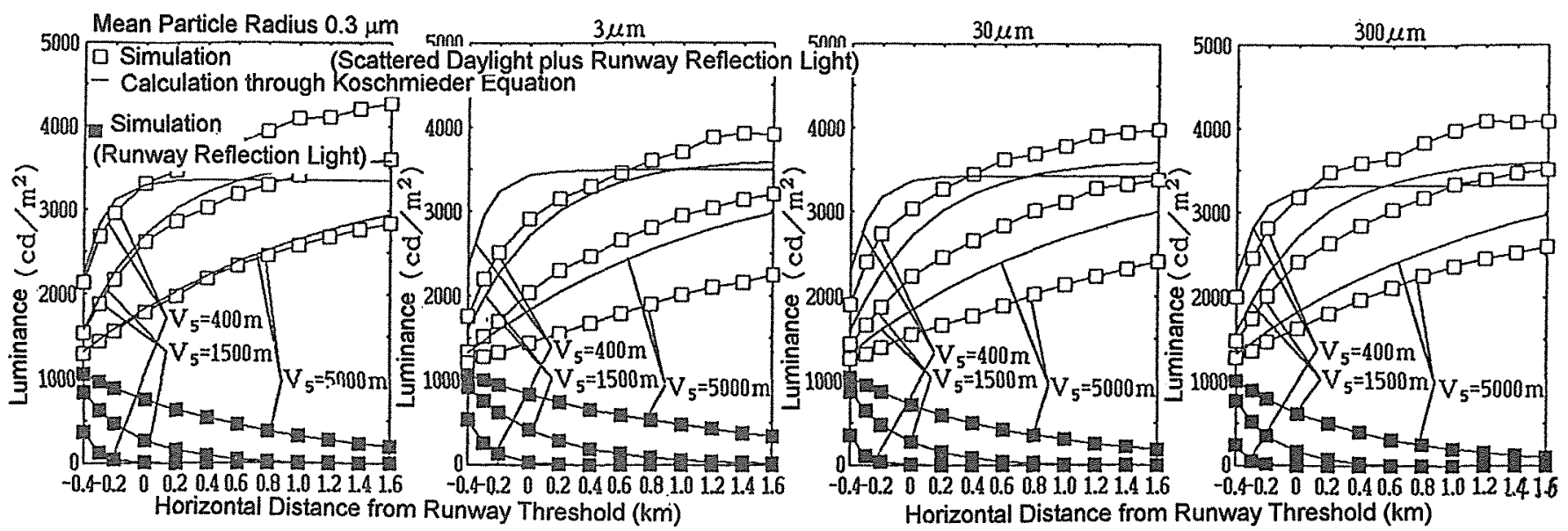

Fig. 10 Additional Luminance with Scattered Daylight and Runway Refrection Light (Cloudy Sky) 


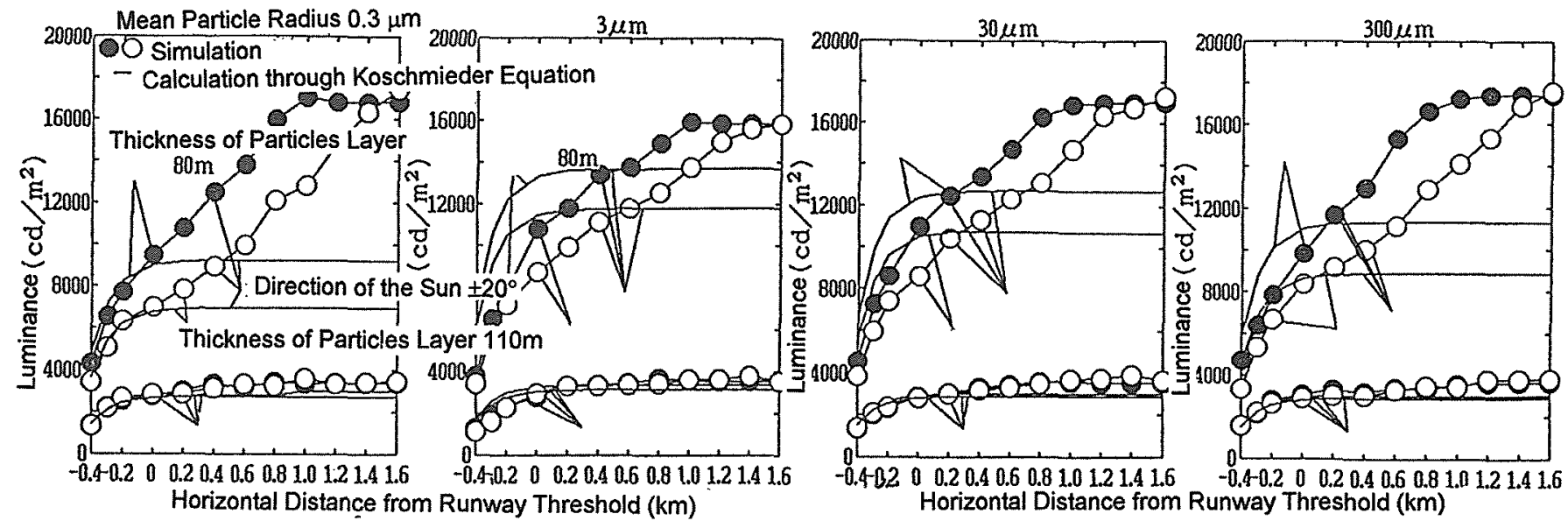

Fig. 11 Additional Luminance with Scattered Daylight and Runway Reflection Light (Clear Sky)

luminance and the luminance calculated through Koschmieder equations. However, the maximum difference was approximately $30 \%$. The effect of particle size distribution was not as large as in the case of the scattered airport light.

\subsubsection{In CIE Standard Clear Sky}

Additional luminance with scattered daylight and runway reflection light, simulated in a CIE standard clear sky, is shown in Fig. 11. Above the particles layer, the illuminance from unobstructed sky was assumed to be $20,000 \mathrm{~lx}$, the sunlight horizontal illuminance 5,000 lx, the solar altitude 20 degrees, and $V_{5} 400 \mathrm{~m}$. Thinner particles layer was shown to give earlier increase in the additional luminance. When the aiming point is seen from above the layer, a thicker layer was shown to give a slightly higher additional luminance. (Under the present conditions, the top of particles layer is at approximately $1.1 \mathrm{~km}$ from the runway threshold with the layer thickness of $80 \mathrm{~m}$, and at approximately $1.7 \mathrm{~km}$ with $110 \mathrm{~m}$.)

Comparison of the simulated luminance with the apparent surface luminance $\mathrm{L}_{\mathrm{r}}$, calculated through Koschmieder equation, showed that these values did not coincide with each in the same manner as these values in a overcast sky when observation distance was not much more than visibility $V_{5}$.

Intensity of the forward scattered light was considerably higher than that of the backward scattered light, when scattered on particles; accordingly, the additional luminance was higher when the plane is landing toward the sun, and lower when landing in the opposite direction. (The landing direction is assumed to be equal to the direction of observation.) Although there are large differences in simulated luminance by direction of observation, the calculation through Koschmieder equation keeps a same level of differences as the simulation, as long as the sky luminance on horizon in direction of observation is used as $\mathrm{L}_{\mathrm{h}}$ within the range of ouservation distance not exceeding visibility $V_{5}$ to a great extent.
The effect of particle size distribution was slightly higher than in the case of the overcast sky, and was not much higher than in the case of scattered airport light.

\section{Conclusion}

A simulation program, analyzing space distribution of scattered light using Monte Carlo Method, was produced on the basis of the scattering characteristics obtained with Mie equation for scattering. Using this, we could investigate how the characteristics of particles in the air and conditions of the sky affect the additional luminance with airport lamplight and with daylight. The results are as follows:

(1) Back calculation of the scattering efficiency, via simulated visibility $V_{5}$ based on specification for the transmissometer used in RVR observation apparatus, showed that the scattering efficiency converges to 1 as the mean particle radius increases. This result coincides with the apparent contradiction of Mie equation indicated by H.S.W. Massery et al. that the apparent extinction section is equal to the geometrical section for an large object.

(2) Additional luminance with scattered airport light was confirmed to reach the maximum value higher than 6 $\mathrm{cd} / \mathrm{m}^{2}$ in the vicinity of aiming point (i.e. point $\mathrm{A}$ ) when the mean particle radius is $0.3-300 \mu \mathrm{m}$ and visibility $V_{5}$ is more than $400 \mathrm{~m}$, which suggests that the scattered airport light may affect the brightness of airport light at night and in the twilight.

(3) Comparison of the the simulated luminance additional luminance with scattered daylight plus runway reflection with the simulated luminance, calculated through Koschmieder equation, revealed that the two do not perfectly coincide, the simulated luminance being lower when observation distance was below visibility $\mathrm{V}_{5}$, and the simulated luminance still increasing even beyond the visibility $V_{5}$. 
(4) When the mean particle radius is $0.3-300 \mu \mathrm{m}$, intensity of forward scattering on particles was considerably higher than that of backward scattering; accordingly, the additional luminance with scattered daylight plus runway reflection was higher at the landing toward the sun than in an opposite direction, when the sky condition seen from above the particles layer was assumed to be CIE standard clear sky.

(5) The particle size distribution (or probability density of scattering angle) does not have much effect on space distribution of scattered light, when the luminous element distribution is relatively uniform like sky.

The following subjects still are left for future investigation:

(1) Calculation and visual display of the additional luminance distribution with scattered airport light and scattered daylight.

(2) Quantitative analysis of effects of additional luminance distribution, with scattered airport light and scattered daylight, on the brightness for each airport light.

(3) Calculation of background luminance for each visibility in consideration of scattered airport light and scattered daylight, and of appropriate luminous intensity for the lights.

(4) Investigation and analysis on the effect of veiling reflection on a windshield of an airplane on the brightness of each airport light.

We would like to express our acknowledgment to the officers at the Aviation Bureau and the Meteorological Agency for offering us the materials on airport light and RVR observation apparatus.

\section{REFERENCES}

(1) Foundation for Aviation Promotion: Aeronautical Lighting, Foundation for Aviation Promotion (1986) 136-141

(2) Deirmendjian, D.: Scattering and Polarization Properties Water Clouds Hazes in the Visible and Infrared, Applied Optics 3-2 (1964) 187 196

(3) Harrison, H., Herbert, J. and Waggoner, P.: MieTheory Computations of Lider and Nephelometric Scattering Parameters for Power Law Aerosols, Applied Optics 11-12 (1972) 2880 2885

(4) Bauer, E.: The Scattering of Infrared Radiation from Clouds, Applied Optics 3-2 (1964) 197 202

(5) Laws, J. O. and Parsons, D. A.: The Relation of Raindrop-sizeto Intensity, Transaction American Geophysical Union 24 (1943) 452 460

(6) Born, M. and Worf, E.: Principle on Optics III, Publishing Bureau, Tokai University (1975) 966

(7) Research Committee for Appropriate Luminous Intensity of Aeronautical Light, IIlum. Engng. Inst. Jpn.: Investigation and Research Report on Appropriate Luminous Intensity of Aeronautical Light 